\title{
Maybe we aren't that different after all: Faculty perceptions of grade 7-12 teaching as a career
}

\author{
Jared B. Breakall ${ }^{1}$, Savannah L. Logan ${ }^{1}$, Richard L. Pearson $\mathrm{III}^{2}$, Brian A. Pyper ${ }^{3}$, and Wendy K. \\ Adams $^{1}$ \\ ${ }^{1}$ Department of Physics, Colorado School of Mines, 1500 Illinois Street, Golden, CO 80401 \\ ${ }^{2}$ Physical Sciences Department, Embry-Riddle Aeronautical University, 1 Aerospace Boulevard, Daytona \\ Beach, FL 32114 \\ ${ }^{3}$ Department of Physics, Brigham Young University Idaho, 525 S Center St. Rexburg ID 83460
}

\begin{abstract}
Nearly half of STEM majors in the United States express interest in becoming a grade 7-12 teacher, yet as a nation we face a shortage of qualified math and science teachers. Studies have found that misperceptions about grade 7-12 math and science teaching are impacting student career choices. As part of the Get the Facts Out project, this work addresses faculty perceptions of grade 7-12 teaching because faculty play an important role in student career decisions. Additionally, understanding how faculty perceptions of grade 7-12 teaching differ may inform targeted efforts to change perceptions in the future. In this study, nearly 500 college STEM faculty members' perceptions of grade 7-12 teaching were measured using a newly developed survey. Faculty perceptions were then compared based on department affiliation, position type, and gender. No significantly practical differences were found based on these demographics. Implications for STEM teacher recruitment are discussed.
\end{abstract}

2020 PERC Proceedings edited by Wolf, Bennett, and Frank; Peer-reviewed, doi.org/10.1119/perc.2020.pr.Breakall

Published by the American Association of Physics Teachers under a Creative Commons Attribution 4.0 license.

Further distribution must maintain the cover page and attribution to the article's authors. 


\section{INTRODUCTION}

In the United States there is a shortage of highly qualified grade 7-12 teachers [1] with physics, chemistry, and math having some of the most significant shortages [2,3]. Many high school teachers in these subjects lack even basic qualifications to teach with 63,66 , and 38 percent of physics, chemistry, and math teachers, respectively not holding a degree in their major assignment and/or lacking teacher certification [4]. This teacher shortage is concerning because well-prepared teachers are the most important factor in highquality, pre-college STEM education [5]. Additionally, it has been shown that when students are taught by teachers who have a degree in their content area, those students are more likely to be successful in college and to enroll as STEM majors [6]. In order to properly feed the STEM pipeline in the US and stay at the forefront of technological advancement, highly qualified grade 7-12 science and math teachers are critical.

Contrary to this STEM teacher shortage, interest level in teaching among STEM majors is relatively high, with approximately half of STEM majors expressing some level of interest in teaching as a career [7]. One reason for the disparity between this relatively high interest level in teaching and the severe STEM teacher shortage is the fact that people have been shown to hold misperceptions about grade 7-12 teaching as a career [7].

The Get the Facts Out (GFO) project was started to change the conversation around STEM teacher recruitment by sharing accurate information about the benefits of teaching as a profession. As part of this effort, customizable recruitment materials were created to assist with "getting the facts out" about teaching. One specific aim of the GFO project is to characterize and then inform college STEM faculty's perceptions so they may become informed advocates of grade 7-12 teaching as a profession. This is particularly important because STEM majors often look to faculty for career advice [8].

In this paper we evaluate data collected from physics, chemistry, and math faculty at $\sim 40$ different institutions of higher education. We look to see whether differences exist in the perceptions of grade 7-12 teaching by faculty's department, position type, or gender. We and other members of the teacher preparation community have hypothesized that differences may exist due to variation in faculty's lived experiences. Additionally, being aware of any differences that exist based on these demographics will inform best practices for sharing the facts about the profession.

In this study, we aimed to measure the perceptions of grade 7-12 teaching among college STEM faculty and then analyze if differences in these perceptions exist by demographic. As such, the research questions guiding this study are:
1. What differences by department, position type, or gender exist in how faculty perceive grade 7-12 teaching as a career?

2. Do differences in perceptions of grade 7-12 teaching indicate the need to create resources that are specific to the different populations (e.g. Chemistry vs. Physics faculty)?

\section{METHODS}

In order to answer these questions, there were three main methodological efforts, namely, the development of an instrument to measure faculty perceptions of grade 7-12 teaching, the appropriate sampling of college STEM faculty, and the statistical analysis of differences in perceptions of teaching as a career.

\section{A. Instrument development, validation, and scoring}

To measure faculty perceptions of grade 7-12 teaching as a career, an instrument known as the Perceptions of Teaching as a Profession in Higher Education (PTaP.HE) (pronounced P-taffy) was developed. The instrument consists of 35 Likert scale items (on a 5-point strongly disagree to strongly agree scale) and 5 selected response items. The items in the instrument measure different aspects of faculty's perceptions of grade 7-12 math and science teaching as a career and takes approximately 10 minutes to complete. The PTaP.HE was developed based on a previously developed instrument known as the Perceptions of Teaching as a Profession (PTaP) which was designed to measure the perceptions of grade $7-$ 12 math and science teaching among college students. Some example items from the PTaP.HE are shown below:

- "I think grade 7-12 math or science teaching would be an enjoyable career day-to-day"

- "I regularly discuss grade 7-12 math or science teaching as a career option with students"

The development and validation of the PTaP.HE followed accepted instrument development guidelines [9,10]. This process included: (1) Establishing topics that are important to faculty and teacher recruiters, (2) Identifying the various ways faculty thinking can deviate from expert thinking about these topics through individual interviews and focus groups, (3) Creating a likert-scale instrument with some open-ended survey questions to probe faculty thinking more broadly, (4) Conducting validation interviews with both novices and subject experts on the survey statements, and (5) Administering the survey to faculty broadly and running statistical tests on the results. Further detail can be found in the forthcoming development and validation paper.

As part of the statistical analysis and to facilitate interpretation of PTaP.HE results, a reduced-basis factor 
analysis was performed to identify statistically valid underlying factors within the survey. As such, 10 factors (categories) were identified, with 3-10 survey items associated with each category (Table I).

TABLE I: Empirical categories as determined through exploratory factor analysis for the PTaP.HE.

\begin{tabular}{c}
\hline PTaP.HE Categories \\
Facts About Teaching \\
Salary Accuracy \\
Teaching is a Good Career \\
Teacher Satisfaction \\
Respects the Profession \\
Advising and Support \\
Teaching Advocate \\
Teaching is a STEM Profession \\
Faculty Support \\
Career Options \\
\hline \hline
\end{tabular}

The instrument is scored according to a percent favorable (expert-like) and percent unfavorable scoring system as seen in other perceptions instruments such as the Colorado Learning Attitudes about Science Survey (CLASS) and CLASS-Chem [11,12].

For example, for a given category each faculty participant receives a score for the percent of statements in that category where their response is consistent with the expert response. The expert response, in many cases, is fact-based, and the expert-like response is simply the correct answer. For a portion of the items, the perceptions of those that are successfully involved with the recruiting and preparation of teacher candidates served as the expert response.

The percent agreement scores for each faculty participant in the category are then averaged (as a mean) for the particular data set. This value is then reported as the percent favorable score for the category (e.g. Facts About Teaching). The same process is followed to calculate the percent disagreement with the expert. If a participant chooses neutral on a statement, their response to that statement is not included in either the percent agreement or the percent disagreement scores. We will only report the percent favorable scores in this paper for ease of interpretation.

\section{B. Faculty sampling and participant demographics}

Departments were recruited to be GFO quantitative sites via the PhysTEC network [13], American Chemical Society Hach sites [14], and through email invitation by the Mathematical Association of America. At some institutions all three department types participated but it was not required. Quantitative sites agree to complete the PTaP and the PTaP.HE each year for five years. Year 1 data were collected from April, 2019 - March 2020. The quantitative site contact was asked to solicit faculty responses from their department. Incentives included a yearly report of student and faculty perceptions as well as professional quality usertested, research-based recruitment resources.

For this analysis we included those who answered the department, position type, and gender questions so that the same data could be used for all three comparisons. This data set includes approximately 500 faculty from $\sim 40$ institutions of higher education (IHEs). The IHEs consisted of bachelors, masters, and Ph.D. granting institutions from all areas of the country.

The demographic information by department, position type, and gender are shown in Table II. The gender question asked, "I identify as: Female, Male, Prefer not to say, Other (specify)". Note that in the Gender analysis, due to small sample size and lack of fit for statistical analysis, participants identifying as "Other" could not be included in the analyses.

\section{Statistical analysis}

To compare the effect of faculty's department affiliation, position type, and gender on their perceptions of grade 7-12 teaching as a profession, PTaP.HE category scores were compared between each set of demographics using a two-sided Fisher's exact test [15]. Fishers exact is used to evaluate statistical differences in count data [15]. Furthermore, Cramér's V [16,17] was calculated as a measure of effect size for each comparison that was found to be significantly different. Cramer's V suggests small, medium, and large effects at values of $<0.3,0.3-0.5$, and $>0.5$, respectively [16].

We chose Fisher's exact test for this analysis for two reasons. First, our data is nominal rather than continuous since there are between only four and nine possible scores for each category due to the number of statements associated with each category. Second, the number of participants who received certain scores were less than five for several scores making Fisher's exact test more appropriate than other non parametric tests such as Chi-square. All statistical analyses were conducted in R software.

\section{RESULTS}

To visualize PTaP.HE survey results in a way that allows for easy comparison of 10 category scores across various demographics, radar plots were used. The "spokes" of the plots are the empirical categories within the survey which were determined by the exploratory factor analysis. The

TABLE II. Demographic information of participants

\begin{tabular}{cc|cc|cc}
\hline \hline Department & $\begin{array}{c}\text { Participants } \\
(\mathbf{n = 4 9 5})\end{array}$ & Position Type & $\begin{array}{c}\text { Participants } \\
(\mathbf{n = 4 9 5})\end{array}$ & $\begin{array}{c}\text { Participants } \\
(\mathbf{n = 4 9 8})\end{array}$ \\
\hline Math & 156 & Tenured & 296 & Male & 307 \\
Physics & 196 & Tenure track & 92 & Female & 166 \\
Chemistry & 143 & FT Non-Tenure & 86 & Unreported & Other \\
& & PT Non-Tenure & 21 & Other \\
\hline \hline
\end{tabular}

The 'Unreported' category in the Gender column includes participants who chose "Prefer not to say" for that item 


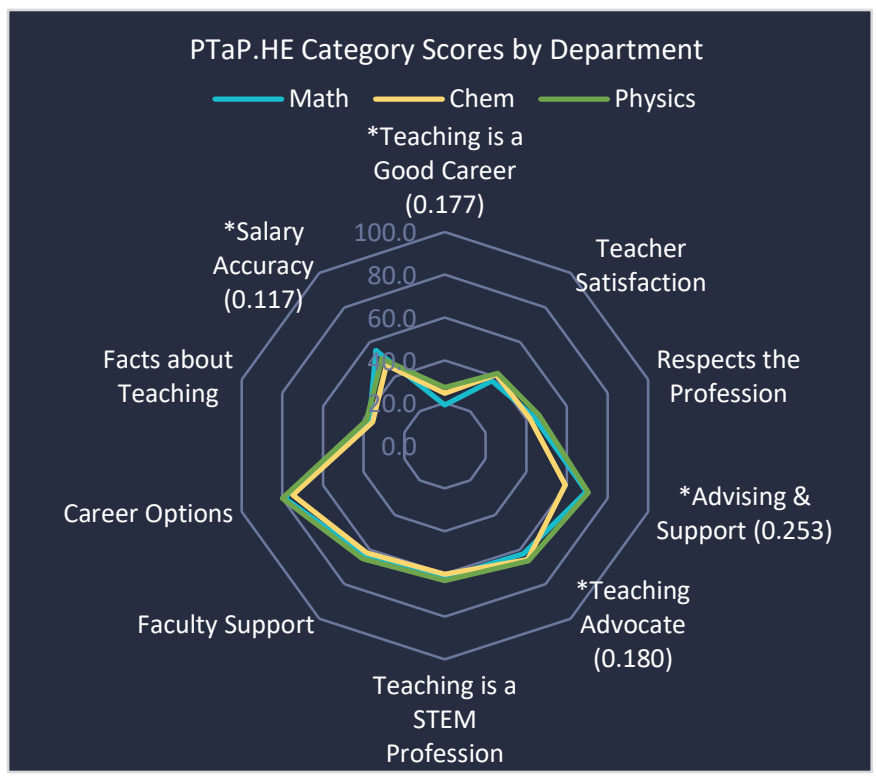

FIG. 1. PTaP.HE average percent favorable by category for Physics, Chemistry and Math faculty. Asterisks represent significance at $\mathrm{p}<0.05$; values within parenthesis are the associated Cramér's V as a measure of effect size.

scale represents percent favorable scores ranging from 0 to 100 , where 100 would be perfect agreement with the expert. Asterisks on the plots represent significant differences at the $\mathrm{p}<0.05$ level. Next to the asterisk is the Cramér's V value as a measure of effect size. Radar plots and statistical comparisons by department affiliation, position type, and gender will now be presented.

\section{A. Department affiliation}

Results indicate that the effect of department affiliation on PTaP.HE category scores were mostly insignificant at the p $<0.05$ level (Fig. 1). In categories where a significant difference was detected ("Teaching is a Good Career", "Advising \& Support", and "Teaching Advocate"), Cramér's $\mathrm{V}$ suggests these differences are small $(\mathrm{V}<0.3)$ and likely of little practical significance. Differences by department status were also not apparent during faculty interviews. Overall, these results suggest that faculty-facing resources for sharing facts about the teaching profession do not need to differ for physics, chemistry or math faculty.

\section{B. Position Type}

Results indicate that the effect of position type ("Tenured", "Tenure track", "Full-time (FT) non-tenure track", or "Part-time (PT) non-tenure track") on perceptions of grade 7-12 math and science teaching were also mostly insignificant at the $\mathrm{p}<0.05$ level (Fig. 2). In the category where a significant difference was detected ("Salary accuracy"), Cramér's V suggests this difference is small (V< 0.3 ) and likely of little practical significance. Overall, these

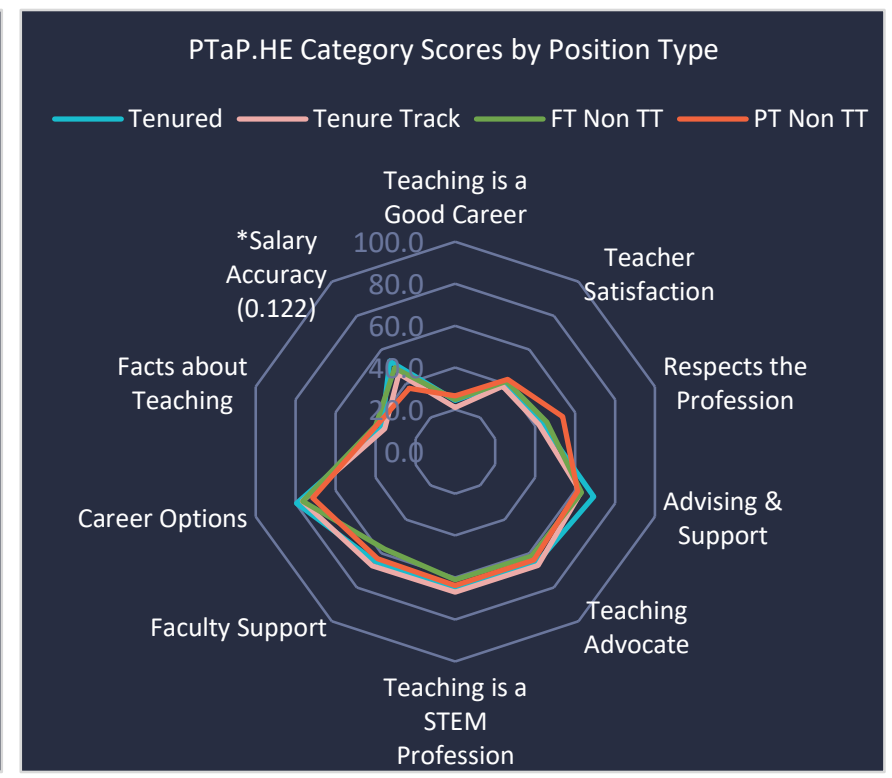

FIG. 2. PTaP.HE average percent favorable by category for Tenured, Tenure Track, Full-time Non-Tenure Track and PartTime non-Tenure Track faculty. Asterisks represent significance at $\mathrm{p}<0.05$; values within parenthesis are the associated Cramér's V as a measure of effect size.

results suggest that faculty-facing resources and efforts to share the facts about the teaching profession do not need to differ for different types of faculty.

\section{Gender}

Results indicate that the effect of gender ("Male", "Female", or "Unreported") on perceptions of grade 7-12 math and science teaching were mostly insignificant at the p $<0.05$ level (Fig. 3). In categories where a significant difference was detected ("Teaching advocate", "Teaching is a STEM profession", and "Facts about teaching"), Cramér's $\mathrm{V}$ suggests these differences are small and likely of little practical significance $(\mathrm{V}<0.3)$. Overall, these results suggest that faculty's gender has little to no effect on their perceptions of grade 7-12 math and science teaching and therefore efforts to share the facts about the profession can be consistent for all faculty.

\section{Overall perceptions of grade 7-12 teaching among college STEM faculty}

When the sample is looked at as a whole, we gain insights into how college STEM faculty perceive grade 7-12 math and science teaching as a career (Fig. 4). Faculty's perceptions tend to be lowest in the categories related to teachers and their careers, specifically Teaching as a Good Career, Facts about Teaching, Teacher Satisfaction, and Respect for the Profession. In contrast, faculty perceptions are highest in categories related to advising and student career options. In other words, faculty perceive that they advise students that teaching is a good career; however, their 


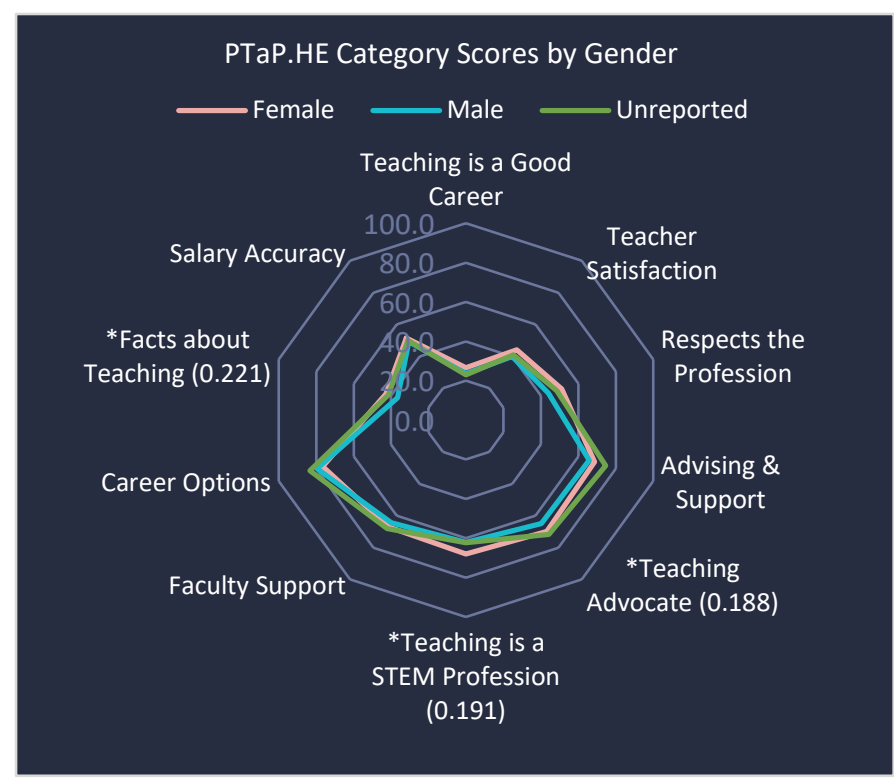

FIG. 3. PTaP.HE category scores by Gender. Asterisks represent significance at $\mathrm{p}<0.05$; values within parenthesis are the associated Cramér's V as a measure of effect size.

personal perceptions of teachers and the teaching career are not strong.

\section{CONCLUSIONS AND LIMITATIONS}

\section{A. Conclusions}

Surprisingly, no differences of any practical significance were found between faculty from different departments, between faculty by position type, or between faculty by gender in how they perceive grade 7-12 teaching as a career. This was unexpected because as faculty demographics differ, one may suspect that their experiences would also differ in ways that would influence their perceptions of grade 7-12 teaching. The fact that faculty members from various backgrounds generally have similar perceptions of grade 712 teaching provides evidence, in addition to previously conducted faculty interviews, that we can approach our efforts to change perceptions of grade 7-12 teaching in a more uniform way than one may suspect.

To understand what that uniform approach may consist of, it is important to comment on the perceptions of college STEM faculty as a whole. In general, as can be seen in Fig 4 , although faculty members perceptions can be improved in all categories, their perceptions tend to be lowest in Teaching is a Good Career, Teacher Satisfaction, Respect for the Profession, and Facts about Teaching.

Due to these deficiencies in STEM faculty's perceptions of grade 7-12 teaching, and due to the lack of differences found by department, position type, or gender, these results suggest that regardless of demographic, we need to focus our efforts to address faculty's misperceptions in these critically low areas.

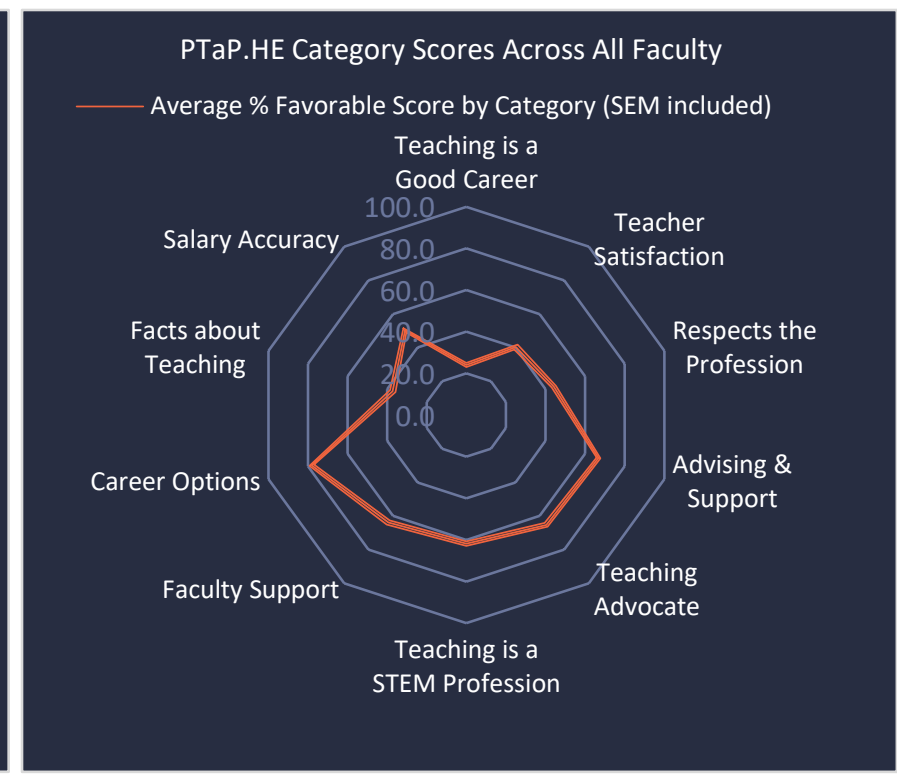

FIG. 4. Average PTaP.HE category scores among college STEM faculty. Line thickness represents the standard error on the mean within each category.

To do so, we suggest using the research-based, usertested [12] resources available at getthefactsout.org. These resources include faculty-facing brochures, posters, and PowerPoint presentations designed to share facts about careers in grade 7-12 math and science teaching. Additionally, the resources are fully customizable so they can be appropriate and useful in any situation.

Because STEM students often turn to college faculty members for career advice, it is important that faculty members are informed advocates of the teaching profession. As such, these findings inform efforts to improve perceptions of college STEM faculty members regarding grade 7-12 teaching, and to recruit more highly qualified STEM teachers in the United States.

\section{B. Limitations}

Due to our recruitment efforts' focus on departments that are actively working to recruit students into math and science teaching, it is likely that these data may be skewed to those who have an investment in STEM teacher preparation and potentially more expert-like perceptions of the profession compared to the average U.S. STEM faculty member.

\section{ACKNOWLEDGMENTS}

The authors would like to thank William Hunter for his insight. We'd also like to thank the GFO project team and all the faculty participants who made the time to complete the survey. This work is supported by the NSF under Grant Nos. $1821710 \& \underline{1821462}$. Any opinions, findings, and conclusions or recommendations expressed in this material are those of the author(s) and do not necessarily reflect the views of NSF. 


\section{REFERENCES}

[1] N. Malkus, K. M. Hoyer, and D. Sparks, Teaching vacancies and difficult-to-staff teaching positions in public schools (NCES 2015-065), no. November, pp. 128, (2015).

[2] Educator Supply \& Demand in the United States Report (Slippery Rock, PA, 2014).

[3] Aragon, S, (2016). Teacher Shortages: What We Know. Teacher Shortage Series. Education Commission of the States, (May), 1-12. Retrieved May 22, 2020 from https://eric.ed.gov/?id=ED565893.

[4] J. Hill and C. Stearns, Education and Certification Qualifications of Departmentalized Public High SchoolLevel Teachers of Selected Subjects: Evidence from the 2011-12 Schools and Staffing Survey. NCES 2015-814 Natl. Cent. Educ. Stat. (2015).

[5] President's Council of Advisors on Science and Technology, Prepare and Inspire: K-12 Education in Science, Technology, Engineering, and Math (STEM) for America's Future (Washington DC, 2010).

[6] Lee, S. W., and Mamerow, G. (2019) Understanding the role cumulative exposure to highly qualified science teachers plays in students' educational pathways. J. Res. Sci. Teach 56(10), 1362-1383.

[7] M. Marder, R. . Brown, and M. Plisch, Recruiting Teachers in High-Needs STEM Fields: A Survey of Current Majors and Recent STEM Graduates, A Report for the American Physical Society Panel on Public Affairs (College Park, MD, 2017).

[8] Major Influence: Where Students Get Valued Advice on What to Study in College. Strada Education Network, (2017).

[9] W. K. Adams and C. E. Wieman, (2011) Development and validation of instruments to measure learning of expert-like thinking. International Journal of Science Education, 33(9), 1289-1312. https://doi.org/10.1080/09500693.2010.512369

[10] Standards for Educational and Psychological Testing American Educational Research Association, (2014).

[11] Adams, Wendy K., \& Wieman, C. E. (2011). Development and validation of instruments to measure learning of expert-like thinking. International Journal of Science Education, 33(9), 1289-1312.

https://doi.org/10.1080/09500693.2010.512369

[12] J. Barbera, W. K. Adams, C. E. Wieman, and K. K. Perkins, Modifying and validating the Colorado learning attitudes about science survey for use in chemistry $J$. Chem. Educ. 85, 1435 (2008).

[13] See https://www.phystec.org. Retrieved June 4, 2020.

[14] See https://www.acs.org/content/acs/en/funding-andawards/hachprograms.html. Retrieved June $4^{\text {th }}, 2020$.

[15] M. Katz, Study Design and Statistical Analysis: A Practical Guide for Clinicians (Cambridge University Press, 2006).

[16] Fritz, C. Morris, P. and Richler, J. Effect size estimates: Current use, calculations, and interpretation J. Exp. Psychol. Gen. 141, 2 (2012).

[17] C. J. Ferguson, Prof. An Effect Size Primer: A Guide for Clinicians and Researchers Psychol. Res. Pract. 40, 532 (2009). 